\title{
Empirical vulnerability curves for Italian mansory buildings: evolution of vulnerability model from the DPM to curves as a function of accelertion
}

\author{
Giulio Zuccaro ${ }^{1}$ (D) . Francesca Linda Perelli ${ }^{1}$ - Daniela De Gregorio ${ }^{1}$. \\ Francesco Cacace ${ }^{1}$
}

Received: 30 January 2020 / Accepted: 8 September 2020 / Published online: 14 October 2020

(C) The Author(s) 2020

\begin{abstract}
In the framework of the emergency management in the case of seismic events, the evaluation of the expected damage represents a basic requirement for risk informed planning. Seismic risk is defined by the probability to reach a level of damage on given exposed elements caused by seismic events occurring in a fixed period and in a fixed area. To this purpose, the expected seismic input, the exposed elements and their vulnerability have to be correctly evaluated. The aim of the research is to define a correct model of vulnerability curves, in PGA, for masonry structures in Italy, by heuristic approach starting from damage probability matrices (DPMs). To this purpose, the PLINIVS database, containing data on major Italian seismic events, has been used and supported by "critical" assumption on missing data. To support the reliability of this assumption, two vulnerability models, considering or not the hypothesis on the missing data, have been estimated and used to calculate the seismic scenario of the L'Aquila 2009 earthquake through the IRMA (Italian Risk MAp) platform. Finally, a comparison between the outcomes elaborated by IRMA platform and the observed damage collected in the AEDES forms, has been done.
\end{abstract}

Keywords Masonry buildings · Vulnerability curves $\cdot$ Empirical approach

Giulio Zuccaro

zuccaro@unina.it

Francesca Linda Perelli

francescalinda.perelli@unina.it

Daniela De Gregorio

daniela.degregorio@unina.it

Francesco Cacace

cacace@unina.it

1 PLINIVS-LUPT Study Centre, University of Naples "Federico II”, Via Toledo, 402 Napoli, Italy 


\section{Introduction}

The first step to plan any operational measure during and after a seismic emergency is the damage assessment of the exposed elements. In this framework, it is possible to develop risk or scenario analyses. The "seismic risk" is defined as the cumulative assessment of the potential total damage caused by the all possible events that can occur in a considered area in a fixed time period. On the other hand, a "seismic scenario" is the damage probabilistic distribution, in a given geographical area, caused by a single seismic event with a given intensity (chosen as "reference scenario"), with assigned probability of occurrence. Risk is, therefore, the combination of scenarios. In both risk/scenario analyses three aleatory variables have to be considered according to the convolution:

\section{Risk $=$ Hazard $\times$ Exposure $\times$ Vulnerability}

The "hazard" is the probability to reach seismic input values in a fixed area and in a predetermined time window. The "exposure" is the qualitative and quantitative geographic distribution of the different elements at risk (population, buildings, infrastructures, activities and facilities) in the examined area, whose conditions and/or efficiency could be damaged, modified or destroyed by the occurrence of the seismic event. The "vulnerability" is the response of an exposed element at risk to a given seismic event. It can be defined as the probability that an exposed element at risk reaches a given level of damage, according to a certain measurement scale, under the effects of a natural event of given intensity. The correct assessment of the three risk factors is fundamental to define the risk.

The vulnerability can be estimated using three different approaches: empirical/observational, analytical/mechanical and hybrid. In the first case, relations among typological features, hazard values and levels of damage are defined using collected data after seismic events. In the second one, numerical simulations of the behaviour of some typologies of buildings (with assigned typological features) are performed increasing the seismic input value, in way to estimate the evolution of the damage. In the third case, the vulnerability model is obtained combining the empirical outcomes and the analytical ones.

Some examples of observational approaches are reported in Benedetti et al. (1988) in which it is proposed a seismic vulnerability risk evaluation for old urban nuclei, or in Riuscetti et al. (1997) in which a criteria for the seismic vulnerability assessment of masonry buildings in some italian regions of moderate seismicity have been developed. About mechanical approaches, some important works in literature have been developed by D'Ayala and Speranza (2003) who define the collapse mechanisms and seismic vulnerability of historic masonry buildings is defined, and by Borzi et al., who introduce a simplified pushover-based earthquake loss assessment (SP-BELA) Method for Masonry Buildings.

Vulnerability can be represented in Damage Probability Matrices (DPMs-discrete information with respect to the hazard value) or in vulnerability curves (continuous information with respect to the hazard value). The first DPM proposal was put forward by Whitman (1973) after the San Fernando earthquake, based on a statistical sample of 1600 buildings, and it was later developed for Italian territories by Braga et al. (1982) based on the damage detected after the 1980 Irpinia earthquake on a statistical sample of 38,000 buildings. In addition, Kappos (1995) obtained DPMs through a hybrid procedure, combining data on past seismic events and nonlinear dynamic analysis outcomes. A similar work has also been developed by Zuccaro et al. (2000) who have provided DPM considering the main Italian seismic events. 
The definition of vulnerability as continuous information in respect to the seismic input value has been introduced by Spence et al. (1991) who proposed a continuous scale of seismic intensity using the Martin Centre vulnerability database. A similar work has been proposed by Orsini (1999) based on the data related to the Irpina 1980 seismic event. Subsequently, other authors as Rossetto et al. (2013), Lagomarsino and Giovinazzi (2006) and Zuccaro and Cacace (2009) proposed a direct correlation between seismic value input, in terms of acceleration, and levels of damage.

In 2018, at the request of European Community, the Italian Civil Protection promoted a technical board for a research activity with the aim of developing vulnerability models of Italian ordinary buildings (masonry and reinforced concrete) to produce seismic risk maps at national scale. The maps have been developed through the IRMA (Italian Risk MAp) platform, a tool developed by Italian Civil Protection in cooperation with Eucentre Foundation (Borzi et al. 2018), that have the aim of evaluating the damage caused by expected Italian seismic events in a fixed time window or for a particular occurred seismic event (scenario analysis). In terms of hazard, exposure and vulnerability, the IRMA functionalities are the following. The platform derives the hazard input only in PGA, assuming a uniform value for each municipality. This value of PGA is based on shakemaps, for the scenario analyses, and probability functions provided by Italian technical regulations (NTC 2018), for risk analyses. About the exposure, the platform adopts buildings typologies at national scale provided by the National Institute of Statistics in the 2001 (ISTAT 2001 database) and classified according to the vertical structure (masonry and reinforced concrete). The user can assign, for the whole national territory, the distribution of vulnerability classes (A, B, C1, D1 for masonry and C2, D2 for reinforced concrete) based on a combination of number of floors and age of buildings. For the vulnerability, the platform allows to define the parameters of the vulnerability curves in PGA, defined only as lognormal functions, characterized by two parameters, mean $\mu$ and standard deviation $\sigma$.

The contribution of the research group of the PLINIVS Study Centre (University of Naples Federico II, Italy), is framed in this contest created by the Italian Civil Protection. The activities developed by the teamwork have been focused on the updating and the conversion into vulnerability curves of DPMs developed in the past by the authors (Zuccaro et al. 2000) for Italian masonry structures through a heuristic approach. The contribution of the group have been inserted in the IRMA platform and, for this reason, it has been developed in terms of PGA. The work involves the development of two models of vulnerability curves; both of them have been validated through the outcomes of the L'Aquila scenario 2009 and the most reliable of the two models has been considered and officially implemented in IRMA. The analyses developed exploit the PLINIVS database that includes data on buildings damaged by major Italian seismic earthquakes and collected through several first level surveys forms for the post-earthquake damage assessment $\left(\mathrm{GNDT}^{(1)}\right.$ II level, AEDES $^{(2)}$, Irpinia, etc.), which have the aim of identifying the typological, damage and usability features of residential buildings soon after the event. The forms include metrical and typological data and the damage conditions, also aimed at a first repair and/or retrofit costs evaluation and allowing to create costs scenarios for different unitary contributions associated to different damage thresholds.

In the database, information has been standardized, in terms of typological features and levels of damage, and DPMs have been estimated for three vulnerability classes of masonry buildings. The vulnerability curves have been assessed through a regression method on obtained DPMs, exploiting two different approaches. The first uses the information included in the database only, while the second approach consists in adding some assumptions in terms of damages on those buildings that haven't been surveyed, and correcting the 
survey data introducing a weight (representative of the reliability of the dataset) depending on the completeness of the information. For this reason, the curves obtained with the first method are, in this paper, defined as outcomes "without revisions" and the second ones are considered as outcomes "with revisions".

(1) GNDT-Gruppo Nazionale Difesa Terremoti (National Group for Earthquake Defence).

(2) AEDES-Agibilità E Danno in Emergenza Sismica (Agibility and damage in seismic emergency).

The paper includes six section. The first one contains the description of the PLINIVS database exploited for the definition of the DPM; the second one describes the SAVE method, the tool adopted to assign the vulnerability class at the buildings in the sample; the third section describes the criteria adopted to minimize the dispersion related to the conversation of the hazard from MCS intensity to PGA; the fourth section describes the "without revisions" vulnerability curves and their approximation with the data; the fifth section describes the hypotheses that support the DPMs, the "with revisions" vulnerability curves and their matching of the datasets; the last section includes the outcomes related to the L'Aquila scenario 2009 for both the models.

\section{The PLINIVS database}

The PLINIVS database collects data of the main Italian seismic events like the Irpinia earthquake (1980), Umbria-Marche (1997), Molise-Puglia (1997), Pollino (1998), Emilia (2003), L'Aquila (2009) and Emilia (2012). Information about 240,000 masonry buildings are reported in the database. However, after each event the surveys operations were developed using different forms: the collected data were not homogeneous in terms of typological features and levels of damage. A work to harmonise the data has been done exploiting the common or similar typological features and referring to the EMS'98 guide (Grünthal 1998) for the damage level scale. The correspondence between the damages reported in the forms and the EMS'98 damage is assumed as in (Perelli et al. 2019) and the following levels of damage are considered (Fig. 1): D0: no damage; D1: Negligible to slight damage (no structural damage, slight non-structural damage); D2: Moderate damage (slight structural damage, moderate non-structural damage); D3: Substantial to heavy damage (moderate structural damage, heavy non-structural damage); D4: Very heavy damage (heavy structural damage, very heavy non-structural damage); D5: Destruction (very heavy structural damage).

The assignment of the vulnerability class is done through the S.A.V.E. method (Zuccaro and Cacace, Seismic vulnerability assessment based on typological characteristics. First level procedure S.A.V.E., 2015), a procedure for a quick assignment of the seismic vulnerability according to the classification of EMS'98. The procedure starts from the criteria adopted in the EMS'98, that assigns the vulnerability class on the basis of the vertical structure reducing the uncertainties of the assignment on the basis of other typological features. The considered typological features are summarized in Table 1 . The work envisages the classification of masonry buildings into three types: class A (most vulnerable type), class B (medium vulnerable type) and class C (least vulnerable type). 


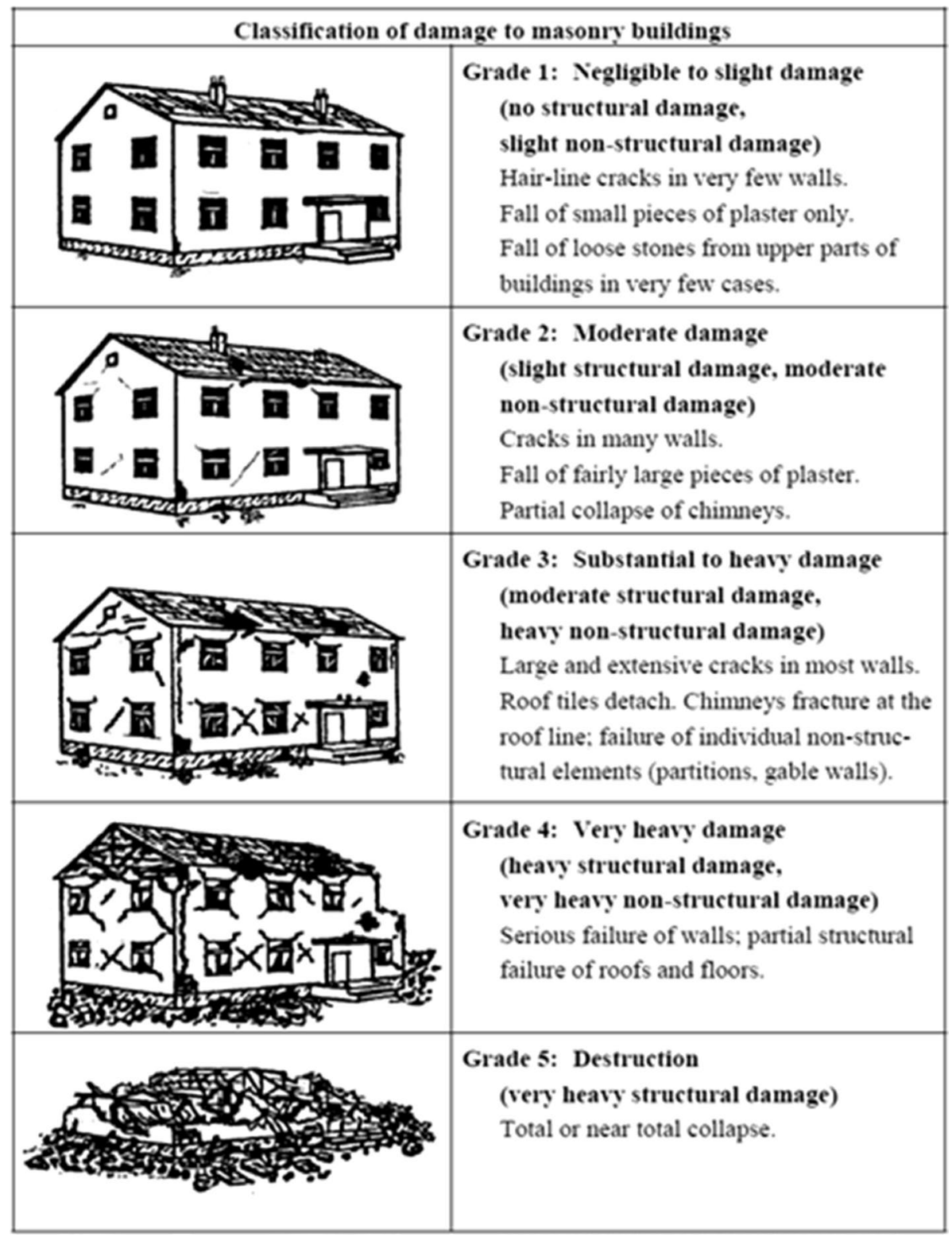

Fig. 1 Levels of damage proposed into the EMS 1998 (Grünthal 1998)

\section{The S.A.V.E. method}

The S.A.V.E. method defines the vulnerability class of a sample building based on the typological and geometrical features reported in Table 1. In particular, a range of building seismic behaviour is defined according to its vertical structure and uncertainties 


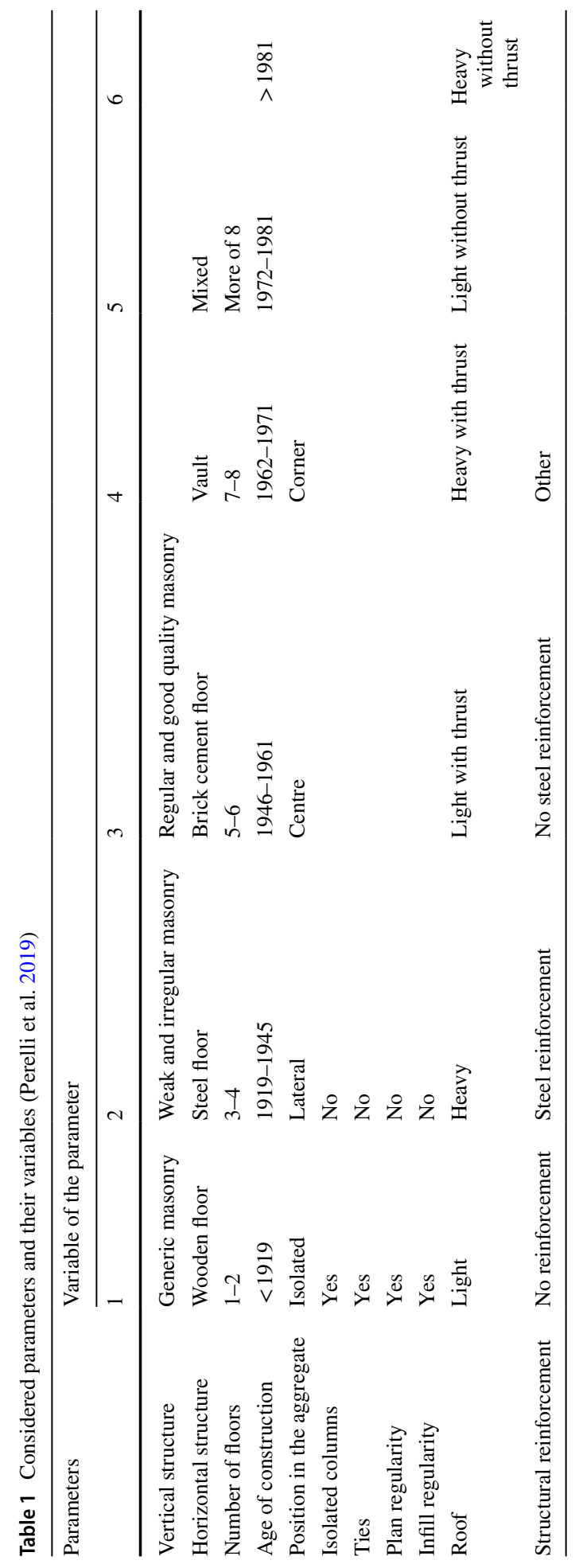


on the seismic response are reduced through the remaining parameters. The procedure defines the classes of Vertical Structure (VS):

- V0- "Generic" masonry (in the absence of information on the quality of the wall structure)

- V1-Weak and irregular masonry.

- V2-Regular and good quality masonry.

In the first step of the procedure, a corresponding Vi class is assigned to each building in the database based on its vertical structure. For each class the response of the related buildings is defined in terms of a Synthetic Damage Parameter $\left(\mathrm{SPD}_{\mathrm{Vi}}\right)$, identifying it as the barycentric abscissa of the damage distribution associated to the considered Vi class. On the basis of the outcomes, three ranges of SPD representative of the VS have been evaluated that represents the behaviour of the Vulnerability Class A (the weak and irregular masonry), class B (generic masonry) and class C1 (regular and good quality masonry). The ranges are summarized in Table 2.

The parameters reported in Table 1 are considered as "vulnerability modifiers", able to improve or worsen the average behaviour of a building under seismic action. Their influence is estimated through the introduction of an $\mathrm{SPD}_{\mathrm{Vi-Pjk}}$ calculated on sample of buildings with a chosen VS and the considered parameter. For example, if the influence of the horizontal structure on "Generic" masonry (V0) buildings has to be estimated, $\mathrm{SPD}_{\mathrm{V} 0-\mathrm{Pjk}}$ value is calculated for V0 with wooden floor sample, V0 with steel floor sample, etc. The influence of the modifier $k$ of the parameter $\mathrm{Pj}$ in the vertical structure $\mathrm{Vi}$ is defined as the difference between $\mathrm{SPD}_{\mathrm{Vi} \text {-Pik }}$ value and the $\mathrm{SPD}_{\mathrm{Vi}}$ value. At the end, the vulnerability class of each building is calculated assuming as the "base" score the average $\mathrm{SPD}_{\mathrm{Vi}}$ value of the class VS belonging to and by adding to it the contributions of all the known parameters by the following Eq. (1)

$$
S P D=S P D_{v}+\sum_{s=1}^{n} q_{s}+\frac{\sum_{j=1}^{m} \sum_{i=1}^{m}\left(p_{j}+p_{i}\right) c_{i j}}{2 m}
$$

in which:

- $\mathrm{q}$ is the influence of the independent parameter

- $\mathrm{p}$ is the influence of the dependent parameter

- $\mathrm{n}$ is the number of independent parameters

- $\mathrm{m}$ is the number of dependent parameters

- $\mathrm{c}_{\mathrm{ij}}$ is the coefficient of correlation between pi and pj parameters (see Zuccaro and Cacace 2015 to deepen)

Table 2 Range of $\mathrm{SPD}_{\mathrm{V}}$ for each vulnerability class

\begin{tabular}{llll}
\hline & $\mathrm{A}$ & $\mathrm{B}$ & $\mathrm{C} 1$ \\
\hline $\mathrm{SPD}_{\mathrm{V}, \text { max }}$ & 5.00 & 2.20 & 1.60 \\
$\mathrm{SPD}_{\mathrm{V}, \text { min }}$ & 2.20 & 1.60 & 0.00 \\
\hline
\end{tabular}




\section{The hazard definition}

The vulnerability curves proposed in this work have to be uploaded in the IRMA platform to produce risk maps at national scale. The platform requires the hazard information in terms of PGA. However, in the forms collected in the PLINIVS database, this data is reported in MCS intensity so a conversation in PGA is necessary.

The problem of conversion of MCS intensity to PGA is still open and under study. The characteristics and definition of the two systems of measurement of shaking are such as to make a really precise correlation impossible, and each of the laws of correlation present in the literature, ultimately, has wide margins of randomness: they are obtained through regressions that always depend on assumptions and compromises. Moreover, a large part of the damage database used is made up of events that occurred in Italy, so it was preferred to adopt a PGA/IMCS conversion that was the result of studies on data recorded in the same territory proposed by Margottini et al. (1992).

In support of the choice made, it can be observed an article of Gomez Caprera et al. (2007) that makes an extensive and detailed examination of different conversation adopted over time (Fig. 2).

It is noted that the report adopted represents good mediation. Faenza-Michelini's conversation, for example, strongly overestimates the intensity for low PGA values and the underestimation for high values of PGA.

Furthermore, in Table 3 is reported the PGA values (source shake-map INGV) and the relative I-MCS calculated with the different formulas.

Comparing these values with the macroseismic intensities actually detected, in particular the minimum values (Rome) and maximum values (L'Aquila), the differences are clear, and it can be observed that the best approximation is that provided by Margottini's conversion.

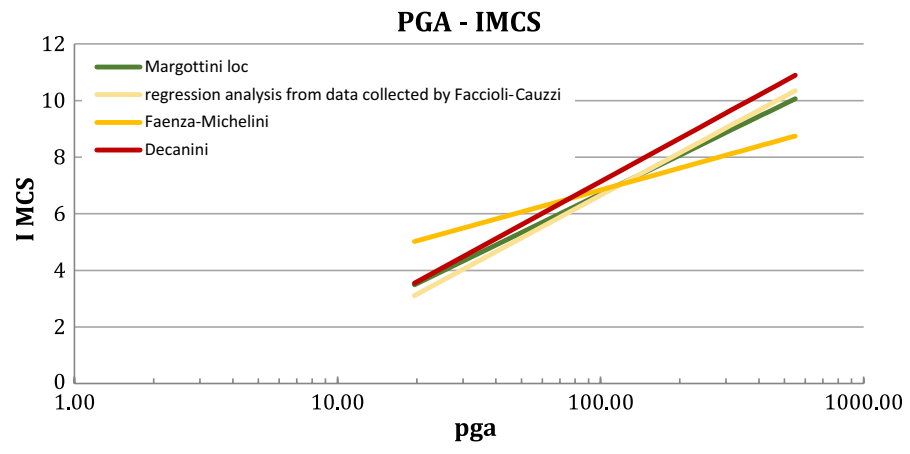

Fig. 2 Conversion of PGA to MCS intensity (Gomez Capera et al. 2007) 
Table 3 Conversion of PGA in MCS intensity for some Italian Cities hit by the seismic event of L'Aquila 2009

\begin{tabular}{lllllll}
\hline & PGA $(\mathrm{g})$ & \multicolumn{2}{l}{ I MCS } & & & \\
\cline { 3 - 7 } & & Margottini & $\begin{array}{l}\text { Faenza- } \\
\text { Michelini }\end{array}$ & Faccioli-Cauzzi & Decanini & DBM 15 \\
\hline L'Aquila & 0.38 & 9.3 & 8.3 & 9.5 & 10.0 & 9 \\
Chieti & 0.03 & 4.4 & 5.5 & 4.1 & 4.6 & 5 \\
Castelvecchio S & 0.14 & 7.3 & 7.2 & 7.3 & 7.8 & 7 \\
Rieti & 0.06 & 5.7 & 6.2 & 5.5 & 6.0 & 5 \\
Roma & 0.03 & 4.3 & 5.5 & 4.0 & 4.4 & $4-5$ \\
Avezzano & 0.08 & 6.2 & 6.6 & 6.1 & 6.6 & 5 \\
\hline
\end{tabular}

\section{Evaluation of the damage probability matrices (DPMs) and the correlated vulnerability curves as a function of the acceleration}

The Damage Probability Matrices (DPMs) associated with the PLINIVS database have been extracted from the data considering the correlations among the vulnerability class, the hazard value and the level of damage. Buildings distribution based on damaged levels are been summarized in Tables 4,5 and 6 for the vulnerability class A, B and

Table 4 Damage Probability Matrix of the masonry buildings for the vulnerability class A

Table 5 Damage Probability Matrix of the masonry buildings for the vulnerability class B

\begin{tabular}{|c|c|c|c|c|c|c|c|}
\hline \multicolumn{2}{|c|}{ Hazard } & \multicolumn{6}{|c|}{ Vulnerability class A } \\
\hline & & \multicolumn{6}{|c|}{ Level of damage } \\
\hline I & pga & D0 $(\%)$ & D1 $(\%)$ & D2 $(\%)$ & D3 (\%) & D4 (\%) & D5 (\%) \\
\hline $\mathrm{V}$ & 0.04 & 19 & 30 & 20 & 18 & 9 & 4 \\
\hline VI & 0.07 & 12 & 30 & 16 & 21 & 13 & 8 \\
\hline VII & 0.12 & 12 & 22 & 20 & 21 & 16 & 8 \\
\hline VIII & 0.20 & 8 & 17 & 22 & 18 & 26 & 9 \\
\hline IX & 0.33 & 6 & 12 & 21 & 18 & 27 & 17 \\
\hline X & 0.54 & 10 & 14 & 12 & 18 & 26 & 19 \\
\hline
\end{tabular}

\begin{tabular}{|c|c|c|c|c|c|c|c|}
\hline \multicolumn{2}{|c|}{ Hazard } & \multicolumn{6}{|c|}{ Vulnerability class B } \\
\hline & & \multicolumn{6}{|c|}{ Level of damage } \\
\hline I & $\mathrm{a}$ & D0 (\%) & D1 $(\%)$ & D2 $(\%)$ & D3 (\%) & D4 (\%) & D5 $(\%)$ \\
\hline V & 0.04 & 25 & 37 & 21 & 11 & 4 & 2 \\
\hline VI & 0.07 & 30 & 34 & 18 & 11 & 5 & 2 \\
\hline VII & 0.12 & 28 & 33 & 21 & 10 & 6 & 2 \\
\hline VIII & 0.20 & 18 & 25 & 25 & 15 & 15 & 3 \\
\hline IX & 0.33 & 12 & 20 & 32 & 15 & 15 & 6 \\
\hline$X$ & 0.54 & 19 & 20 & 18 & 15 & 18 & 10 \\
\hline
\end{tabular}


Table 6 Damage probability Matrix of the masonry buildings for the vulnerability class $\mathrm{C}$

\begin{tabular}{|c|c|c|c|c|c|c|c|}
\hline \multirow{2}{*}{\multicolumn{2}{|c|}{ Hazard }} & \multicolumn{6}{|c|}{ Vulnerability class C } \\
\hline & & \multicolumn{6}{|c|}{ Level of damage } \\
\hline I & $\mathrm{a}$ & D0 (\%) & D1 (\%) & D2 (\%) & D3 (\%) & D4 (\%) & D5 (\%) \\
\hline V & 0.04 & 32 & 44 & 14 & 7 & 3 & 1 \\
\hline VI & 0.07 & 38 & 39 & 12 & 7 & 3 & 1 \\
\hline VII & 0.12 & 45 & 33 & 13 & 6 & 4 & 1 \\
\hline VIII & 0.20 & 31 & 33 & 17 & 8 & 9 & 2 \\
\hline IX & 0.33 & 40 & 28 & 17 & 6 & 6 & 3 \\
\hline $\mathrm{X}$ & 0.54 & 37 & 29 & 16 & 9 & 6 & 3 \\
\hline
\end{tabular}

$\mathrm{C}$ respectively. The seismic input is reported in MCS intensity (I) and in acceleration (PGA) considering its relation with the intensity through the Margottini relation (1992).

With the aim of using the IRMA platform, the vulnerability curves have been assessed as lognormal functions in PGA. To this purpose the minimum square regression method has been applied to the dataset, and the parameters of each vulnerability curve are defined through the Eq. (2)

$$
\operatorname{find}(\lambda, \beta): \min \left\{\left[y_{i}-\log \left(x_{i}, \lambda, \beta\right]^{2}\right\}\right.
$$

in which

- $\mathrm{x}_{\mathrm{i}}$ is the PGA value;

- $\mathrm{y}_{\mathrm{i}}$ is the cumulative distribution of the considered damage associated to the xi value;

- $\lambda$ is the logarithmic mean of the curve;

- $\beta$ is the logarithmic standard deviation of the curve.

In Figs. 3, 4 and 5 are represented the vulnerability curves for the classes A, B and C respectively, and scatter charts of the DPMs values have been overlaid. The parameters of logarithmic mean $\lambda$ and logarithmic standard deviations $\beta$ have been summarized in Table 7. Furthermore, an estimation of the correspondence between the observed data (DPMs) and the continuous curves has been made. In particular, in Table 8 summarises the squares of the differences between the vulnerability curve value and the observed

Fig. 3 Vulnerability curves for the class A (without revisions)

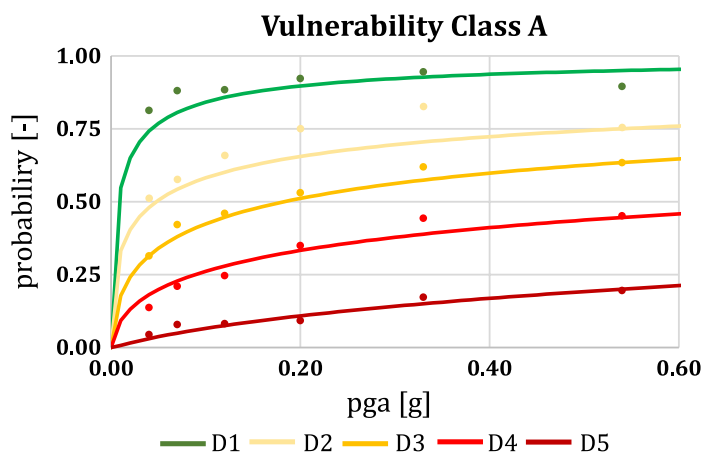


Fig. 4 Vulnerability curves for the class B (without revisions)

Fig. 5 Vulnerability curves for the class $\mathrm{C}$ (without revisions)

Table 7 Logarithmic means and standard deviations of the vulnerability curves (without revisions)

Table 8 Errors of the curves (without revisions) with reference to the DPMs
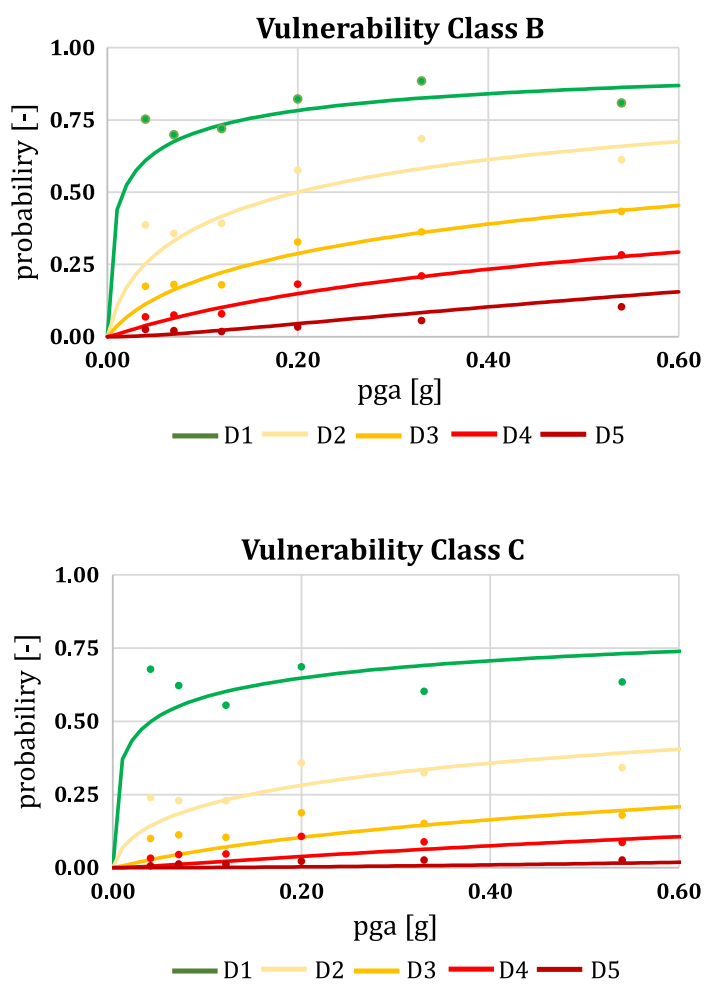

\begin{tabular}{llrrrrr}
\hline VC & Parameters & \multicolumn{2}{l}{ Level of damage } \\
\cline { 3 - 6 } & & \multicolumn{1}{l}{ D1 } & \multicolumn{1}{c}{ D2 } & \multicolumn{1}{c}{ D3 } & \multicolumn{1}{c}{ D4 } & D5 \\
\hline A & $\lambda$ & -4.92 & -3.05 & -1.70 & -0.17 & 1.50 \\
& $\beta$ & 2.61 & 3.59 & 3.15 & 3.35 & 2.52 \\
B & $\lambda$ & -4.12 & -1.61 & -0.23 & 0.69 & 1.12 \\
& $\beta$ & 3.21 & 2.42 & 2.47 & 2.21 & 1.61 \\
C & $\lambda$ & -3.21 & 0.28 & 1.48 & 2.12 & 2.89 \\
& $\beta$ & 4.21 & 3.28 & 2.45 & 2.11 & 1.63 \\
\hline
\end{tabular}

\begin{tabular}{|c|c|c|c|c|c|}
\hline \multirow{2}{*}{$\begin{array}{l}\text { Vulner- } \\
\text { ability } \\
\text { class }\end{array}$} & \multicolumn{5}{|c|}{ Level of damage } \\
\hline & D1 & D2 & D3 & D4 & D5 \\
\hline A & $2.03 \mathrm{E}-02$ & $2.85 \mathrm{E}-02$ & $1.05 \mathrm{E}-02$ & $1.35 \mathrm{E}-02$ & $7.02 \mathrm{E}-03$ \\
\hline B & $2.82 \mathrm{E}-02$ & $3.24 \mathrm{E}-02$ & $1.43 \mathrm{E}-02$ & $8.40 \mathrm{E}-03$ & $8.96 \mathrm{E}-03$ \\
\hline $\mathrm{C}$ & $4.00 \mathrm{E}-02$ & $2.33 \mathrm{E}-02$ & $2.23 \mathrm{E}-02$ & $1.46 \mathrm{E}-02$ & $5.40 \mathrm{E}-03$ \\
\hline
\end{tabular}


data and for each vulnerability curve has been calculated the Square Root of the Sum of Squares value (SRSS), according to the criteria used to estimate the curve (Eq. 2). The high error was found in the D1 vulnerability curve of the class C, but it is lower than $5 \%$ so a good match it between the vulnerability curves and the observed data can be considered.

\section{Heuristic revision of the vulnerability curves}

Although the errors summarized in the Table 7 can be considered acceptable, however errors related to completeness of the buildings damaged survey have to be considered in the definition of the DPMs dataset. In particular, the discrepancy between the percentage of surveyed buildings and the total of the buildings in the affected area could alter significantly the final statistic. In Perelli et al. (2019) the parameter "Completeness Index of the survey activity Ic" has been introduced, defined as the ratio between the surveyed buildings in the area with a fixed PGA value and the total buildings, according to the ISTAT2001 database that represents the last census activity before the considered seismic event. The ISTAT 2001 database contains 'aggregate data' that furnish the number of buildings having a given single characteristic (i.e., building position in the aggregate, material of vertical structure, age of buildings, etc.) for each minimum reference unit, a sub municipal zone, called census area. Therefore, although it would be more appropriate to determine an Ic according to each vulnerability class, however, given the absence of disaggregated information and other significant typological parameters, (horizontal typologies, ties, plan regularity, infill regularity, roof, isolated column, structural reinforcement), it would be necessary to introduce arbitrary assumptions on correlations between these parameters and vulnerability classes distribution. These correlations would be not supported by robust statistics, therefore the use of these models would significantly increase the uncertainties in the assessments of the vulnerability class. For this reason, it has been chosen to adopt a single Ic for each PGA value.

In the Table 9 is shown the completeness index Ic calculated for each PGA value given by the shakemap for the L'Aquila 2009 seismic event. It is also shown that the Ic value increases in accordance with PGA value. In the work the authors consider that "no information" about the buildings damage is, actually, a "no necessary information" for the surveyors, i.e. absence of damage. For this reasons, two important assumptions have been added to the observed data by the authors to review the trend of the vulnerability curves. The first one is to consider a different weight to the observed data, in the equation of the regression method, depending on the survey completeness of the buildings for each area affected by a given PGA value. To this purpose, the equation [2] has been replaced by the equation [3] by introducing of the $\mathrm{Ic}_{\mathrm{i}}$, the completeness index associated to the $\mathrm{x}_{\mathrm{i}}$ value.

in which

$$
\operatorname{find}(\lambda, \beta): \min \left\{I c_{i} \cdot\left[y_{i}-\log \left(x_{i}, \lambda, \beta\right)\right]^{2}\right\}
$$

- $\mathrm{x}_{\mathrm{i}}$ is the PGA value;

- $y_{\mathrm{i}}$ is the cumulative distribution of the considered damage associated to the xi value;

- $\lambda$ is the logarithmic mean of the curve;

- $\beta$ is the logarithmic standard deviation of the curve;

- $\mathrm{Ic}_{\mathrm{i}}$ is the completeness index associated to the $\mathrm{x}_{\mathrm{i}}$ value. 


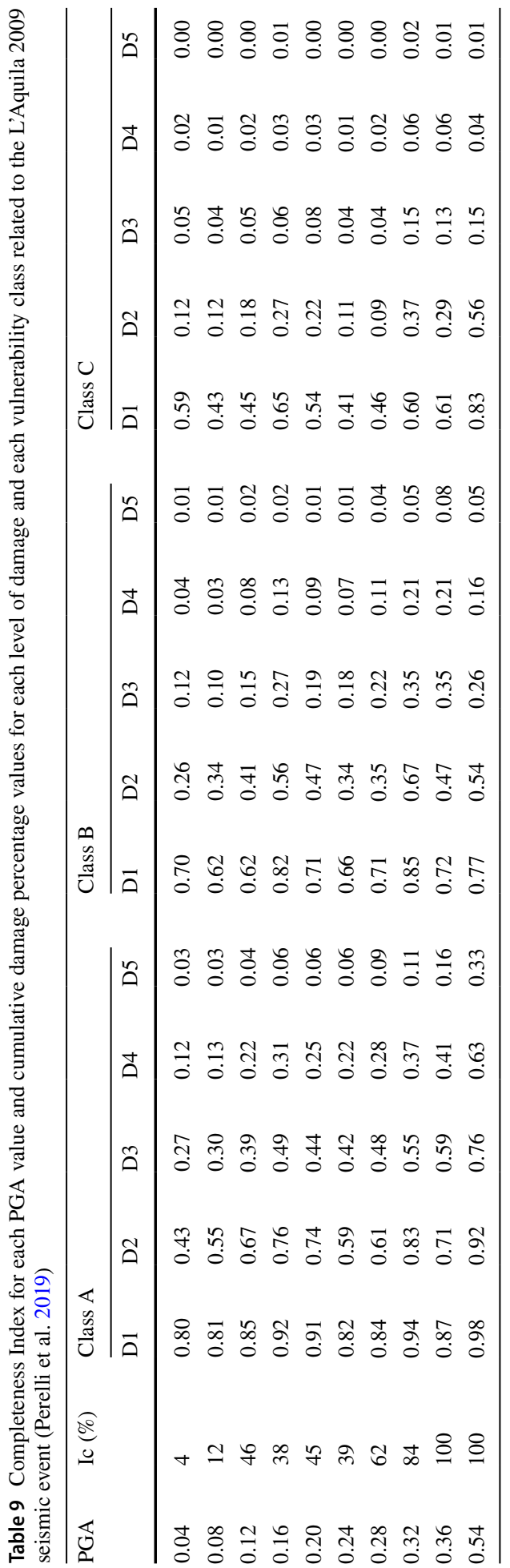


The outcomes of Ic obtained with reference to the L'Aquila 2009 seismic event have been extended to all the dataset, for which the input hazard is available in MCS intensity. Considering the Margottini's conversion, the Ic values introduced in the Eq. (3) have been taken in accordance to the DPM in Tables 3, 4 and 5.

The second one is to introduce basic assumptions that consider the absence of data for low acceleration values (PGA $\leq 0.03 \mathrm{~g}$ ). In particular, it is considered that all undetected buildings in vulnerability classes $\mathrm{B}$ and $\mathrm{C}$ have no damage (D0), the $30 \%$ of undetected buildings in vulnerability class A have a no structural damage (D1) and the remaining $70 \%$ have no damage (D0). In fact, the data collected show that for low PGA values the buildings with slight non-structural damage (D1) are mainly recorded on buildings classified in vulnerability class A. Some elaborations on DPMs (in intensity) produced in the past by the PLINIVS Study Centre has shown that for intensity values in the interval IV-V, corresponding to PGA $=0.03 \mathrm{~g}$ (according to Margottini's conversion), it results that about $30 \%$

Fig. 6 Vulnerability curves for the class A (with revisions)

Fig. 7 Vulnerability curves for the class B (with revisions)

Fig. 8 Vulnerability curves for the class $\mathrm{C}$ (with revisions)
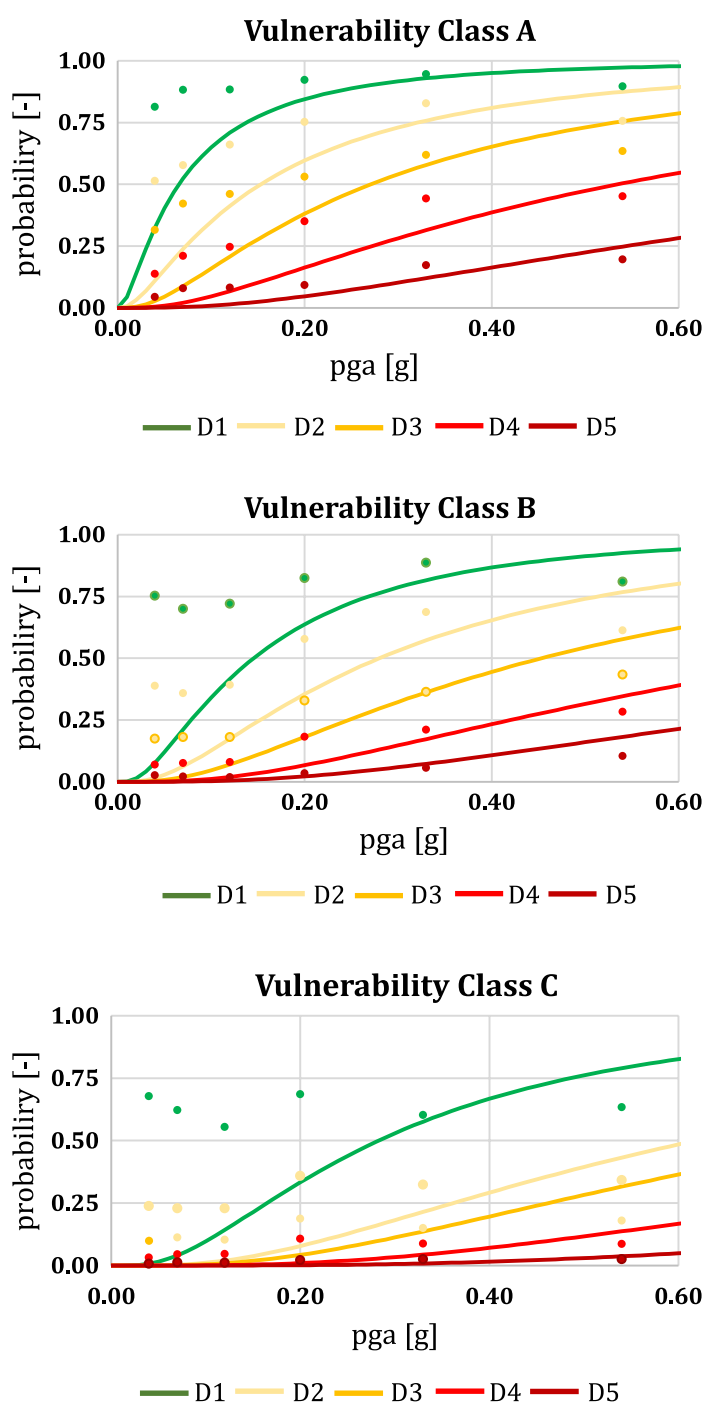
Table 10 Logarithmic means and standard deviations of the vulnerability curves (with revisions)

\begin{tabular}{llrrrrl}
\hline VC & Parameters & \multicolumn{6}{l}{ Level of damage } & & & \\
\cline { 3 - 7 } & & \multicolumn{1}{c}{ D1 } & \multicolumn{1}{c}{ D2 } & \multicolumn{1}{c}{ D3 } & \multicolumn{1}{c}{ D4 } & D5 \\
\hline $\mathrm{A}$ & $\lambda$ & -2.72 & -1.88 & -1.31 & -0.63 & 0.07 \\
& $\beta$ & 1.05 & 1.05 & 1.05 & 1.05 & 1.05 \\
$\mathrm{~B}$ & $\lambda$ & -1.93 & -1.27 & -0.79 & -0.26 & 0.20 \\
& $\beta$ & 0.90 & 0.90 & 0.90 & 0.90 & 0.90 \\
$\mathrm{C}$ & $\lambda$ & -1.26 & -0.48 & -0.23 & 0.26 & 0.82 \\
& $\beta$ & 0.80 & 0.80 & 0.80 & 0.80 & 0.80 \\
\hline
\end{tabular}

Table 11 Errors of the curves (with revisions) with reference to the DPMs

\begin{tabular}{llllll}
\hline $\begin{array}{l}\text { Vulner- } \\
\text { ability } \\
\text { class }\end{array}$ & \multicolumn{5}{l}{ Level of damage } \\
\cline { 2 - 6 } & $\mathrm{D} 1$ & $\mathrm{D} 2$ & $\mathrm{D} 3$ & $\mathrm{D} 4$ & $\mathrm{D} 5$ \\
\hline $\mathrm{A}$ & $1.06 \mathrm{E}-01$ & $1.03 \mathrm{E}-01$ & $9.04 \mathrm{E}-02$ & $6.19 \mathrm{E}-02$ & $2.31 \mathrm{E}-02$ \\
$\mathrm{~B}$ & $1.52 \mathrm{E}-01$ & $9.97 \mathrm{E}-02$ & $5.50 \mathrm{E}-02$ & $2.95 \mathrm{E}-02$ & $1.46 \mathrm{E}-02$ \\
$\mathrm{C}$ & $1.75 \mathrm{E}-01$ & $8.32 \mathrm{E}-02$ & $4.43 \mathrm{E}-02$ & $2.29 \mathrm{E}-02$ & $5.63 \mathrm{E}-03$ \\
\hline
\end{tabular}

of the building in class A reached a damage level equal to D1, while the remaining buildings of other classes did not suffered damage at all.

In Figs. 6, 7 and 8 are represented the updated vulnerability curves for the classes A, B and C respectively, and scatter charts of the DPMs values have been overlaid. The parameters of logarithmic mean $\lambda$ and logarithmic standard deviations $\beta$ are summarized in Table 10. Furthermore, analogous to the previous case, in Table 11 are summarized the squares of the differences between the vulnerability curve value and observed data, and furthermore the SRSS for each vulnerability curve has been calculated, according to the criteria adopted for the calibration of the curve (Eq. 3). It is shown that very high error values can be found especially in the D1 curves: the error is about $24 \%$ for the class A and of $45 \%$ for the classes B and C. Furthermore, in all the classes higher error values are estimated for low levels of damage than for high ones and error decreases as the acceleration value increases.

\section{L'Aquila earthquake 2009: a comparison of the outcomes calculated through the IRMA platform}

To test the vulnerability curves proposed in the Sects. 3 and 4, the impact scenario consequent to the L'Aquila earthquake in 2009 has been assessed through the IRMA tool. For the hazard values, the platform exploits the INGV shakemap of the L'Aquila 2009 event and assigns to each municipality the PGA value corresponding to the centroid of its geometry (Fig. 9). The exposure values are estimated by IRMA through the correlations among three typological parameters (vertical structure, number of floors, age of construction) of the ISTAT2001 database and the distribution of the buildings on the three vulnerability classes A, B and C introduced by the user. The vulnerability parameters have been introduced through mean and standard deviation of the estimated curves. Furthermore, to avoid 


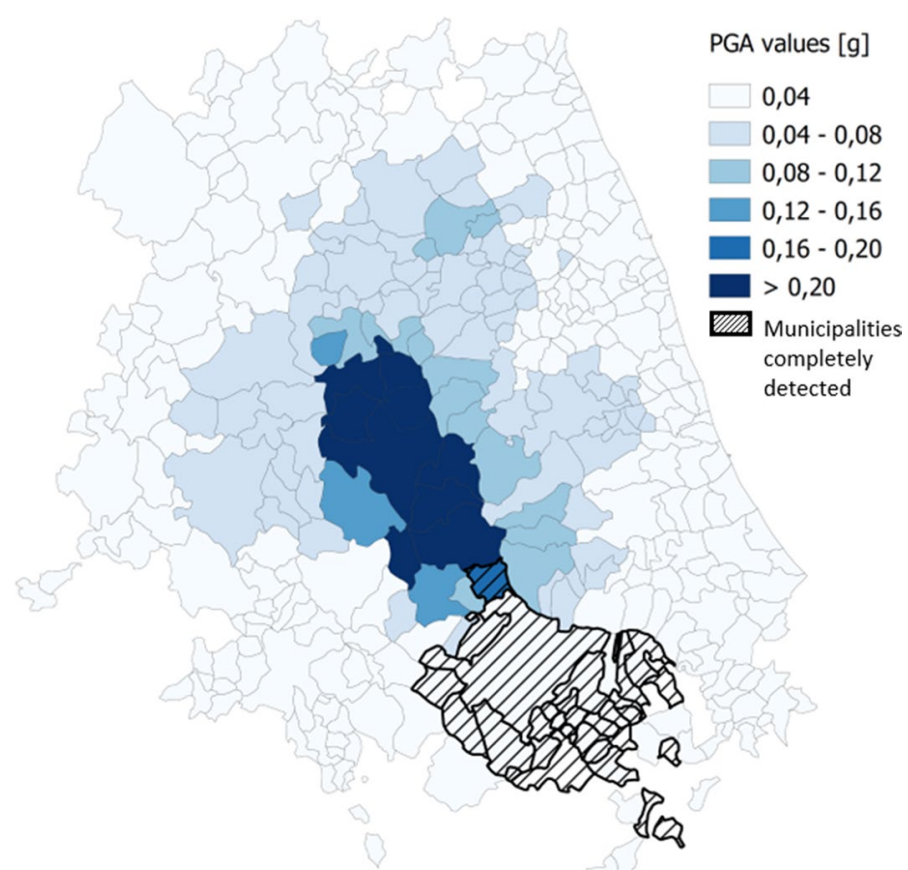

Fig. 9 PGA distribution on for the L'Aquila 2009 event according to the IRMA platform

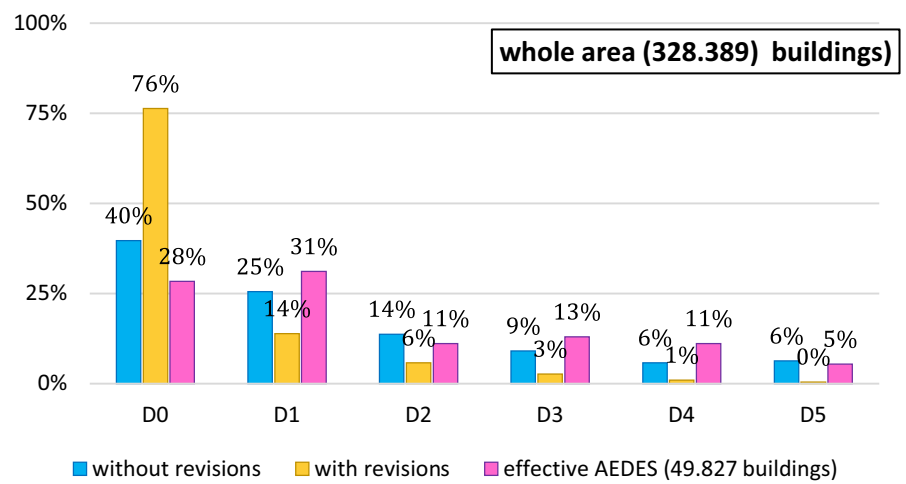

Fig. 10 Buildings distribution on the levels of damage in reference to the whole area and the effective AEDES forms

overstatement problems in areas with low values of PGA, the platform considers a cut off of the curves for $\mathrm{PGA} \leq 0.03 \mathrm{~g}$.

Based on these parameters, the buildings distributions on the levels of damage caused by the L'Aquila seismic event have been calculated using two vulnerability approaches. The outcomes are summarized in Figs. 10, 11, 12, 13 and 14. In particular, Figs. 10 and 11 refer to the outcomes on the whole area affected by the earthquake. In Fig. 10 the buildings 


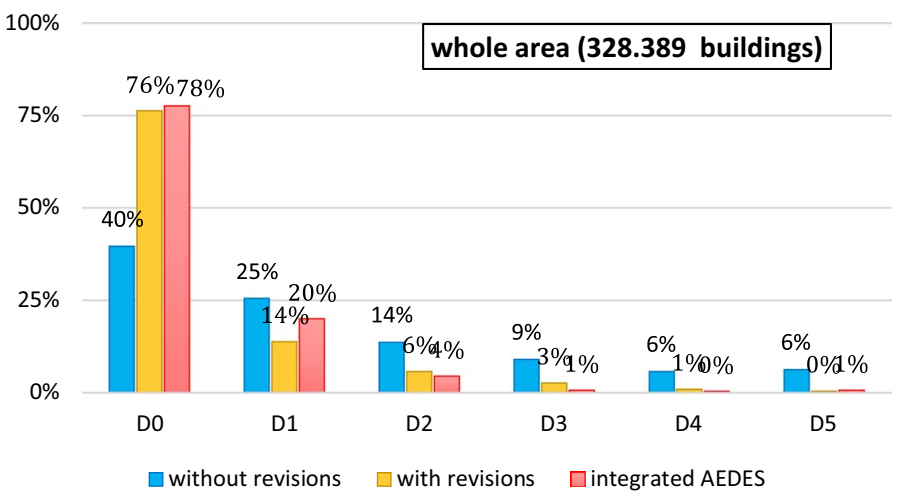

Fig. 11 Buildings distribution on the levels of damage in reference to the whole area and the integrated AEDES form

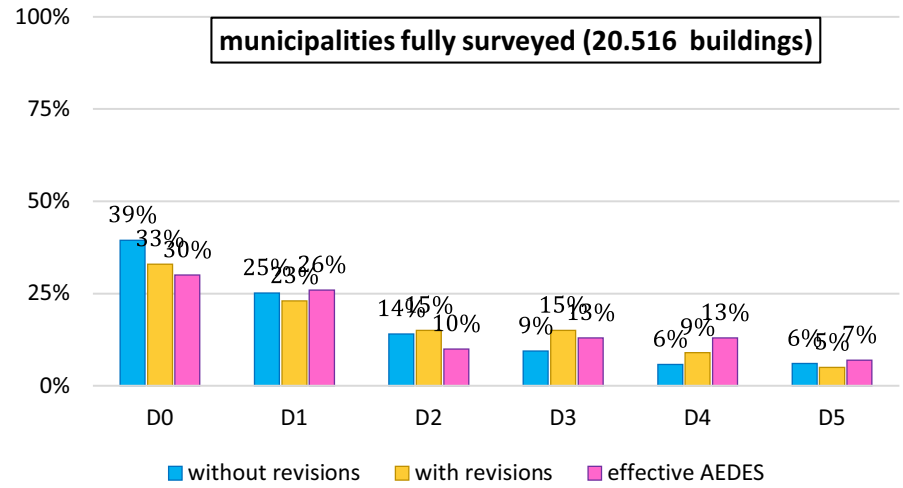

Fig. 12 Buildings distribution on the levels of damage in reference to the municipalities fully detected

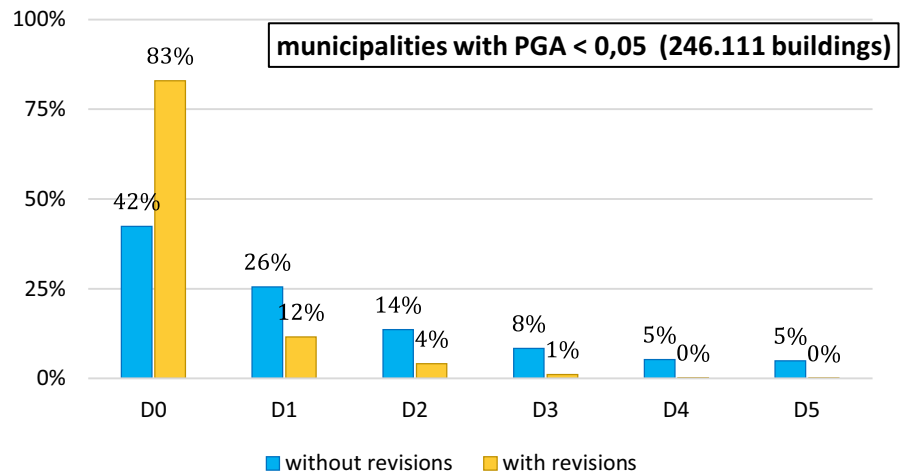

Fig. 13 Buildings distribution on the levels of damage in reference to the municipalities with pga $<0.05 \mathrm{~g}$ 


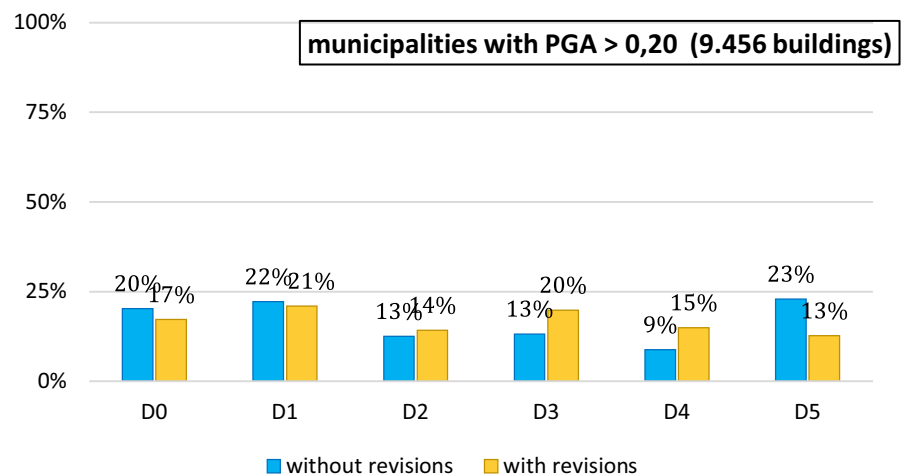

Fig. 14 Buildings distribution on the levels of damage in reference to the municipalities with pga $>0.20 \mathrm{~g}$

distribution on the basis of the AEDES form is estimated considering the effective surveyed buildings only, that are 49.827 out of 328.389 , i.e. the $17 \%$ of the total buildings. Keeping the assumption on accuracy, it can be considered that the reliability of the data is low. Figure 11 shows the outcomes of the two approaches compared to the integrated AEDES, i.e. it is considered that the $30 \%$ of the no surveyed buildings in class A have a level of damage equal to D1 and the remaining $70 \%$ is not damaged and that all no surveyed buildings in classes $\mathrm{B}$ and $\mathrm{C}$ have no damages. It is shown that in the first case there is more similarity of outcomes between the AEDES forms and the "without revisions" model, instead in the second case the match is more evident between the integrated AEDES form and the "with revisions" model. Figure 12 shows the buildings distribution on the levels of damage calculated using the two models and the observed data for the municipalities fully detected by AEDES forms. It's evident that both models have a good consistency with the data.

Furthermore, a comparison between the two models is shown in Figs. 13 and 14, in which damage buildings distribution is calculated for municipalities with $\mathrm{PGA}<0.05 \mathrm{~g}$ and PGA $>0.20 \mathrm{~g}$, respectively. It is shown that high discrepancies can be recorded for low levels of damages and low PGA values and, on the contrary, less differences can be found for high PGA values in all levels of damage. This is obviously justified by the assumptions of the "with revisions" method.

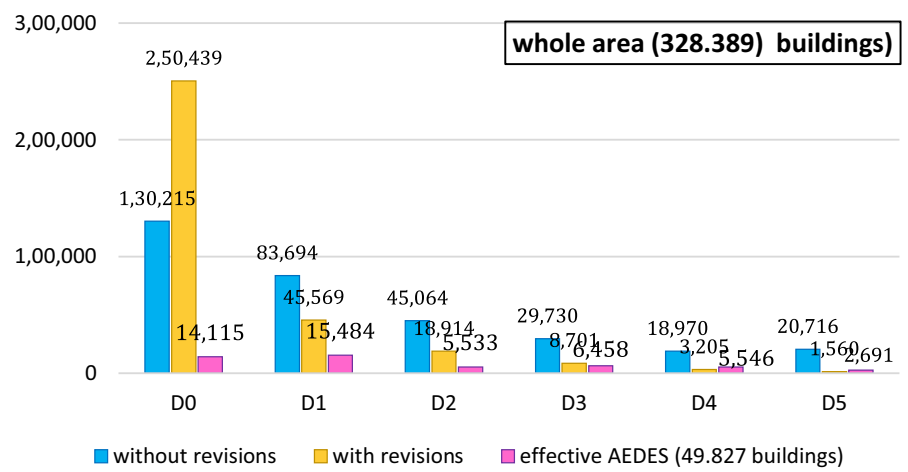

Fig. 15 Number of buildings on the levels of damage in reference to the whole area 
At the end, Fig. 15 summarizes the number of buildings in each level of damage with reference to the whole area. A significant result that must be highlighted is that there is a better match of collapsed buildings between the "with revisions" model and the effective AEDES forms. An analysis of the errors of both methods in reference to effective AEDES forms shows that: both methods overestimate the number of no damaged buildings (D0), but the error of the "with revision" method in reference to the AEDES form is higher; the "without revisions" method overestimates significantly the high levels of damage (D3-D5). This shows that the "with revisions" method is more reliable because while it is reasonable that the AEDES forms are not filled in for undamaged buildings (D0), it is very unlikely that for very damaged buildings (D4-D5) the forms (which is the basis of requests for contributions for seismic improvement and adaptation measures) are not compiled. Furthermore, it is important to note that the "with revisions" method slightly underestimates the number of buildings with high damage levels (D4-D5), but this is caused by the intrinsic error of ISTAT 2001 database which, by failing to distinguish between buildings and aggregates, provides a smaller total number of buildings than the actual one.

\section{Conclusions}

The aim of the paper is to describe the work done within the technical board promoted by Italian civil protection to develop vulnerability curves in terms of PGA for Italian masonry structures, by an heuristic approach. The curves are obtained as lognormal functions through a "critical" empirical method, based on statistical analysis of data of the buildings damage caused by main Italian seismic events, included in the PLINIVS database.

Firstly, a specific analysis of the completeness of the database at low levels of damage (D0-D1) has been done, and some suitable assumptions have been integrated in the database to correlate low levels of damages with soil excitation (PGA). Hence, the curves are derived by regression analysis, on the basis of Macroseismic Intensity observed, transformed into acceleration through the Margottini's conversion.

The validation of the vulnerability curves has been carried out by scenario analyses related to the L'Aquila 2009 seismic event, by using the IRMA platform, a tool developed by the Italian Civil Protection to assess Italian seismic risk maps. A comparison between the obtained outcomes elaborated by IRMA for the vulnerability curves here proposed and the real damage collected after the earthquake using the surveys on the site has been done. It shows the reliability of the curves "with revisions", highlighting how the use of database without additional assumption for no surveyed buildings, generates vulnerability curves that overestimates the high levels of damage (D3-D5).

Future developments include improvement on the accuracy of uncertainties estimated in the analyses of the variables involved (Ader et al. 2017). In particular, future investigation are required on the uncertainty related to the conversion of seismic input values from intensity to PGA and the definition of a robust method to determining the completeness index with a good accuracy for each vulnerability class, according to the ISTAT data. Finally, the authors aim to produce vulnerability models at regional scale able of take into account both specific typological distribution of the area considered and mechanical and typological characteristics of the buildings in each region of Italy. 
Funding Open access funding provided by Università degli Studi di Napoli Federico II within the CRUICARE Agreement.

Open Access This article is licensed under a Creative Commons Attribution 4.0 International License, which permits use, sharing, adaptation, distribution and reproduction in any medium or format, as long as you give appropriate credit to the original author(s) and the source, provide a link to the Creative Commons licence, and indicate if changes were made. The images or other third party material in this article are included in the article's Creative Commons licence, unless indicated otherwise in a credit line to the material. If material is not included in the article's Creative Commons licence and your intended use is not permitted by statutory regulation or exceeds the permitted use, you will need to obtain permission directly from the copyright holder. To view a copy of this licence, visit http://creativecommons.org/licenses/by/4.0/.

\section{References}

Ader T, Grant DN, Free M, Villani M, Lopez J, Spence R (2017) An unbiased estimation of empirical lognormal fragility functions with uncertainties on the ground motion intensity measure. J Earthquake Eng. https://doi.org/10.1080/13632469.2018.1469439

Benedetti D, Benzoni G, Parisi MA (1988) Seismic vulnerability risk evaluation for old urban nuclei. Earthquake Eng Structural Dyn, pp 183-201.

Borzi B, Crowley H, Pinho R (2008) Simplified pushover-based earthquake loss assessment (SP-BELA) Method for Masonry Buildings. Int J Architectural Heritage. https://doi.org/10.1080/1558305070 1828178

Borzi B, Faravelli M, Onida M, Polli D, Quaroni D, Pagano M, Di Meo A. (2018) Piattaforma IRMA (Italian Risk MAps). GNGTS, pp 382-388.

Braga F, Dolce M, Liberatore D (1982) Southern Italy November 23, 1980 Earthquake: a statistical study of damaged buildings and a ensuring review of the M.S.K.-76 Scale. CNR-PFG n.503. Roma.

D'Ayala D, Speranza E (2003) Definition of collapse mechanisms and seismic vulnerability of historic masonry buildings. Earthquake Spectra 19(3):479-509

Grünthal G (1998) European macroseismic scale, Luxemburg.

Gomez Capera AA., Albarello D, Gasperini P (2007) Aggiornamento relazioni fra l'intensità macrosismica e PGA. Progetto DPC-INGV S 1.

ISTAT (2001) $14^{\circ}$ censimento della popolazione e delle abitazioni.

Kappos AJ, Pitilakis K, Stylianidis KC (1995) Cost-benefit analysis for the seismic rehabilitation of buildings in thessaloniki, based on a hybrid method of vulnerability assessment. In: Proceedings of the fifth international conference on seismic zonation, Vol 1, Nice, France, pp 406-413

Lagomarsino G, Giovinazzi S (2006) Macroseismic and mechanical models for the vulnerability and damage assessment of current buildings. Bullet Earthquake Eng, pp 415-443.

Margottini C, Molin D, Serva L (1992) Intensity versus ground motion: a new approach using Italian data. Eng Geol 33(1):45-58

Orsini G (1999) A model for buildings' vulnerability assessment using the Parameterless Scale of Seismic Intensity (PSI). Earthq Spectra 3(15):463-483

Perelli FL, De Gregorio D, Cacace F, Zuccaro G (2019) Empirical vulnerability curves for Italian masonry buildings. In: $7^{\circ}$ ECCOMAS Thematic Conference on Computational Methods in Structural Dynamics and Earthquake Engineering [COMPDYN], Crete, pp 1745-1758.

Rossetto T, Ioannou I, Grant D (2013) Existing empirical fragility and vulnerability functions: compendium and guide for selection, GEM Technical Report 2013-X. GEM Foundation, Pavia

Riuscetti M, Carniel R, Cecotti C (1997) Seismic vulnerability assessment of masonry buildings in a region of moderate seismicity. Vol 40, Published by INGV, Istituto Nazionale di Geofisica e Vulcanologia, ISSN: 2037-416X

Spence R, Coburn A, Pomonis A (1992) Correlation of ground motion with building damage: the definition of a new damage-based seismic intensity scale. In: Proceedings of 10th world conference on earthquake engineering. Balkema, Rotterdam.

Spence R, Coburn A, Sakai S, Pomonis A (1991) A parameterless scale of seismic intensity for use in the seismic risck analysis and vulnerability assessment. In: International conference on earthquake, blast and impact, Manchester.

Whitman RV (1973) Damage probability matrices for prototype buildings. Structurespublication, vol 380. MIT, Bosto 
Zuccaro G, Cacace F (2009) Revisione dell'inventario a scala nazionale delle classi tipologiche di vulnerabilità ed aggiornamento delle mappe nazionali di rischio sismico. Atti del XIII Convegno ANIDIS "L'ingegneria sismica in Italia". Bologna

Zuccaro G, Cacace F (2015) Seismic vulnerability assessment based on typological characteristics. First level procedure S.A.V.E. Soil Dyn Earthquake Eng, pp 262-269

Zuccaro G, Bernardini A, Gori R, Muneratti E, Paggiarin C, Parisi O (2000) Vulnerability and probability of collapse for classes of masonry buildings. In: Faccioli E, Pessina V (eds) The Catania Project: earthquake damage scenarios for high risk area in the Mediterranean. CNR-GNDT, ROMA, pp 146-158. ISBN: 88-900449-0-X

Publisher's Note Springer Nature remains neutral with regard to jurisdictional claims in published maps and institutional affiliations. 